\title{
Roles of plant hormones in thermomorphogenesis
}

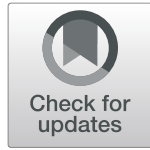

\author{
Hai-Ping Lu, Jing-Jing Wang, Mei-Jing Wang and Jian-Xiang Liu* (i)
}

\begin{abstract}
Global warming has great impacts on plant growth and development, as well as ecological distribution. Plants constantly perceive environmental temperatures and adjust their growth and development programs accordingly to cope with the environment under non-lethal warm temperature conditions. Plant hormones are endogenous bioactive chemicals that play central roles in plant growth, developmental, and responses to biotic and abiotic stresses. In this review, we summarize the important roles of plant hormones, including auxin, brassinosteroids (BRs), Gibberellins (GAs), ethylene (ET), and jasmonates (JAs), in regulating plant growth under warm temperature conditions. This provides a picture on how plants sense and transduce the warm temperature signals to regulate downstream gene expression for controlling plant growth under warm temperature conditions via hormone biosynthesis and signaling pathways.
\end{abstract}

Keywords: Arabidopsis, Auxin, BR, Ethylene, GA, JA, Temperature, Thermomorphogenesis

\section{Introduction}

Plants constantly adjust their growth and developmental programmes in accordance with environmental temperatures (Legris et al. 2017; Vu et al. 2019a). With the global warming effects, such adaptations are quite important for ensuring plant survival, productivity, and ecological distribution (Xu et al. 2020; Sun et al. 2020). Even a modest shift in environmental growth temperature can significantly alter the expression of hundreds of temperature responsive genes, leading to obvious morphological and developmental changes, including hypocotyl and petiole elongation, leaf hyponasty, stomata movement and accelerated flowering, in a process collectively referred to as thermomorphogenesis (Quint et al. 2016; Casal and Balasubramanian 2019; Vu et al. 2019b). The term thermomorphogenesis is analogy to photomorphogenesis (light-mediated growth), to describe the effects of environmental temperature on plant morphology. The process of thermomorphogenesis is similar to skotomorphogenesis (growth in the dark) in

\footnotetext{
* Correspondence: jianxiangliu@zju.edu.cn

State Key Laboratory of Plant Physiology and Biochemistry, College of Life Sciences, Zhejiang University, Hangzhou 310027, China
}

terms of hypocotyl elongation, but the underlying mechanisms could be quite different (Delker et al. 2014). Plant thermomorphogenesis has been widely studied in recent years in view of its climatic association with global warming, a worldwide ecological and agricultural concern. Because increases in global temperature are expected to dramatically reduce crop productivity (Schlenker and Roberts 2009; Nicotra et al. 2010; Rathore et al. 2020), understanding the mechanism of warm temperature responses has become imminent for knowledge-based crop designs to sustain crop production in a changing climate.

Various signaling mediators and associated signaling mechanisms have been revealed in plant responses to warm temperatures (Zhang et al. 2021b). Among them, the PHYTOCHROME INTERACTING FACTOR 4 (PIF4) acts as a central transcription regulator ( $\mathrm{Vu}$ et al. 2019b), which is regulated at both the transcriptional and protein levels (Park et al. 2017; Gangappa and Kumar 2017; Han et al. 2019; Zhang et al. 2017). PIF4 induces the transcription of downstream genes and promotes organ elongation and flowering under warm temperature conditions (Franklin et al. 2011; Sun et al. 2012; Kumar et al. 2012).

\section{Springer}

() The Author(s). 2021 Open Access This article is licensed under a Creative Commons Attribution 4.0 International License, which permits use, sharing, adaptation, distribution and reproduction in any medium or format, as long as you give appropriate credit to the original author(s) and the source, provide a link to the Creative Commons licence, and indicate if changes were made. The images or other third party material in this article are included in the article's Creative Commons licence, unless indicated otherwise in a credit line to the material. If material is not included in the article's Creative Commons licence and your intended use is not permitted by statutory regulation or exceeds the permitted use, you will need to obtain permission directly from the copyright holder. To view a copy of this licence, visit http://creativecommons.org/licenses/by/4.0/. 
Plant hormones, or phytohormones, are endogenous small chemical molecules that play diverse physiological roles in plant growth, development, and environmental stress and defense responses (Verma et al. 2016; Depuydt and Hardtke 2011). These includes seven classical plant hormones, auxin, cytokinin (CK), Gibberellins (GAs), ethylene (ET), abscisic acid (ABA), brassinosteroids (BRs) and Strigolactone (SL) (Peres et al. 2019; Burger and Chory 2020; Binder 2020; Chen et al. 2020; Shu et al. 2018; Cortleven et al. 2019; Zhao 2018). In this review, we summarize and discuss recent research progress on how thermomorphogenic growth is regulated in plants and highlight the important role of phytohormones including auxin, BRs, GAs, and ET in plant thermomorphogenesis. Hypocotyl elongation is one of the earliest phenotypes in plant response to warm temperature, therefore we mainly focused on the shoot thermomorphogenesis in the current paper.

\section{Warm temperature sensing}

Plants precisely sense environmental temperature changes to adjust their growth and development. Multiple warm temperature sensors and thermosensory mechanisms in plants have been identified (Fig. 1). For example, phytochrome B (phyB) was identified as a thermosensor which also acts as a photoreceptor (Legris et al. 2016; Jung et al. 2016). It exists as two interconvertible photochemical forms in plants: the red lightabsorbing Pr and the far-red light-absorbing Pfr (Burgie and Vierstra 2014). The photo-activated Pfr of phyB thermodynamically reverts to the Pr form in darkness, which is termed 'dark reversion' or 'thermal conversion' (Klose et al. 2020). Notably, warm temperatures accelerate the Pfr-to-Pr dark reversion, releasing the inhibitory effect of phyB on PIF4 (Legris et al. 2016; Jung et al. 2016). In addition, the number of phyB-containing photobodies decreases under warm temperature

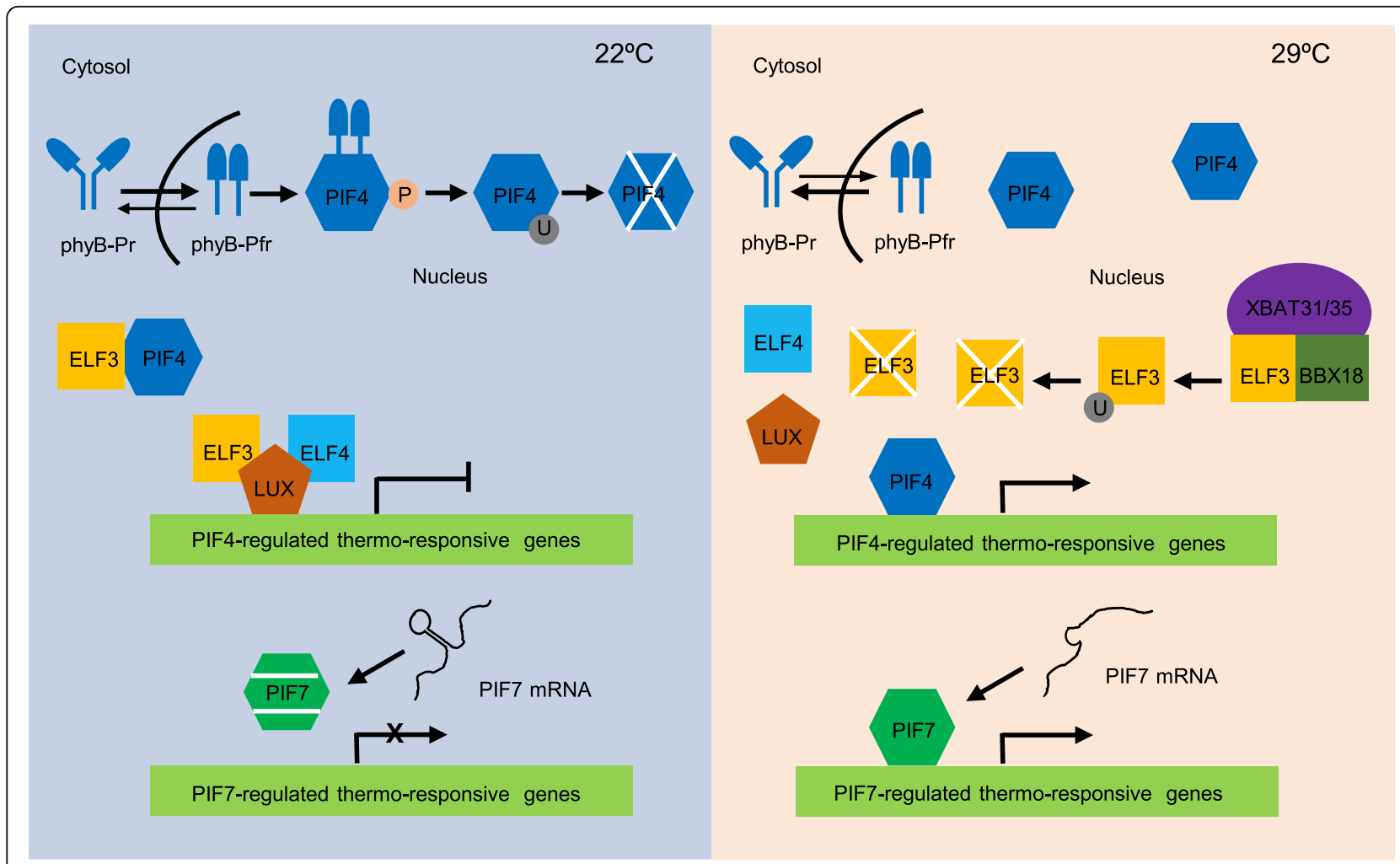

Fig. 1 An overview of the signal transduction and gene regulation in plant thermomorphogenesis. phyB, ELF3 and PIF7 are proposed thermosensors. Both PIF4 and PIF7 are key transcriptional regulators of downstream genes involved in hypocotyl growth. At ambient temperatures $\left(22^{\circ} \mathrm{C}\right.$ ), photoreceptor phyB readily converts from the inactive form Pfr to the active form Pfr, and phyB-Pfr binds to PIF4, leading to PIF4 phosphorylation and subsequently proteasome-mediated degradation; ELF3 functions as a negative regulator of PIF4 by inhibiting the expression of PIF4 together with ELF4 and LUX in the evening complex (EC), and by inhibiting the protein activity of PIF4 independent on EC; the secondary structure of PIF7 mRNA also inhibits the protein translation of PIF7. At elevated warm temperatures $\left(29^{\circ} \mathrm{C}\right)$, the conversation of phyB from Pfr back to Pr is accelerated, therefore releasing the inhibitory effects of phyB on PIF4; ELF3 is degraded by the E3 ubiquitin ligase XBAT31/ 35 together with BBX18, diminishing the inhibitory effect of ELF3 on PIF4; PIF7 mRNA has a conformation change, which enhances PIF7 translation. More PIF4 and PIF7 activities result in faster hypocotyl elongation in Arabidopsis. BBX18, B-box 18; ELF3/4, EARLY FLOWERING 3/4; LUX, LUX ARRHYTHMO; PHYB, phytochrome B; PIF4/7, phytochrome interacting factor 4/7; XBAT31/35, XB3 ORTHOLOG 1/5 IN Arabidopsis thaliana 
conditions (Hahm et al. 2020), demonstrating a thermosensory mechanism controlled by phyB. The rate of thermal reversion of phyB, in particular, is rapid enough to rival that of photoactivation and accelerates with temperature increases of between $10^{\circ} \mathrm{C}$ and $30^{\circ} \mathrm{C}$ (Legris et al. 2016). These intrinsic properties of the phyB molecule enable the activity of phyB to respond to changes in environmental temperatures (Fig. 1).

Early Flowering 3 (ELF3) is a recently proposed thermosensor (Jung et al. 2020). It is also an essential component in the Evening Complex (EC) of plant circadian clock (Nusinow et al. 2011). The ELF3 protein has a prion-like domain $(\mathrm{PrD})$ with embedded polyglutamine (polyQ) repeat, which is important for inducing the formation of protein condensates via liquid-liquid phase separation (Jung et al. 2020). ELF3 recruits ELF4 and LUX ARRHYTHMO (LUX) to repress the transcriptional expression of PIF4 during early night (Nusinow et al. 2011; Thines and Harmon 2010). Therefore, the expression of PIF4 is rhythmic and tightly regulated by the circadian clock (Nozue et al. 2007; Kunihiro et al. 2011). ELF3 also suppresses the protein activity of PIF4 in an EC-independent manner by preventing PIF4 from activating its transcriptional targets in the light (Nieto et al. 2015). The accumulation of ELF3 is reduced under warm temperature conditions via XB3 ORTHOLOG 1 IN Arabidopsis thaliana (XBAT31)- and XBAT35mediated ubiquitination and degradation with the B-box protein BBX18 acting as a scaffolding protein, releasing the repression effects of ELF3 on PIF4 (Ding et al. 2018; Zhang et al. 2021c; Zhang et al. 2021a) (Fig. 1).

PIF4, a bHLH transcription factor in Arabidopsis, induces the expression of downstream genes to promote organ elongation and flowering (Franklin et al. 2011; Kumar et al. 2012). PIF7 is a homologous gene to PIF4, but it is recently reported to be involved in warm temperature sensing (Chung et al. 2020). The secondary structure of PIF7 mRNA has a conformation change in response to warm temperatures, leading to the enhanced translation of PIF7 protein, representing a new type of thermosensing (Chung et al. 2020; Vu et al. 2019a) (Fig. 1). PIF7 also directly promotes thermomorphogenic growth by regulating downstream gene expression alone or together with PIF4 (Fiorucci et al. 2020; Chung et al. 2020).

\section{Auxin and thermomorphogenesis}

Both auxin biosynthesis and auxin signaling are required for PIF4-mediated hypocotyl elongation at warm temperatures (Casal and Balasubramanian 2019). The auxin indole-3-acetic acid (IAA) is synthesized from Ltryptophan, via a main indole-3-pyruvic acid pathway, involving the TRYPTOPHAN AMINOTRANSFERASE OF ARABIDOPSIS (TAA) and YUCCA (YUC) flavin monooxygenase families of enzymes (Table 1) (Won et al. 2011). Free IAA levels in aerial tissues are increased under warm temperature conditions (Gray et al. 1998), which is caused by temperature-mediated binding of PIF4/PIF7 to promoter, and subsequent activation of auxin biosynthesis genes such as YUC8 (Franklin et al. 2011; Sun et al. 2012; Fiorucci et al. 2020). Polar auxin transport is also important for thermoresponses. High temperature enhances shootward auxin transport in roots by promoting the efficient targeting of PINFORMED2 (PIN2) to the plasma membrane. More PIN2 accumulation to the plasma membrane makes it capable of transporting more auxin out of the cell and, thus, of maintaining the optimal cellular auxin concentration to promote root growth and development, which dependents on SORTING NEXIN1 (SNX1) through an endosomal trafficking pathway (Hanzawa et al., 2013). Transcriptomics analysis suggested that a mobile auxin signal connects temperature sensing in cotyledons with growth responses in hypocotyls (Bellstaedt et al. 2019).

Increased intracellular auxin activates a transcriptional cascade mediated by the TRANSPORT INHIBITOR RESPONSE 1/AUXIN-RELATED F-BOX (TIR1/AFB) family of F-box proteins, which functions as the auxin receptor, and the auxin response factors (ARFs) and AUX/IAA families of transcriptional regulators (Salehin et al. 2015). The ubiquitination of AUX/IAA by the auxin-SCF ${ }^{\mathrm{TIR} 1 / \mathrm{AFB}}$ complex targets these negative regulators AUXs/IAAs for proteasomal degradation and relieves their inhibition on ARFs, enabling the expression of downstream gene expression (Salehin et al. 2015). Indeed, auxin responsive genes such as Small auxin up RNA 19 (SAUR19) are induced by warm temperatures (Kim et al. 2020; Ding et al. 2018; Franklin et al. 2011).

\section{BR and thermomorphogenesis}

BRs are the polyhydroxylated steroidal hormones that are ubiquitously present in the plant kingdom (Peres et al. 2019). BR-mediated thermomorphogenesis is mainly mediated by BR-regulated transcription factor, BRASSINAZOLE RESISTANT1 (BZR1) (Ibanez et al. 2018) (Fig. 2). BZR1 becomes dephosphorylated and activated, presumably through the action of the protein phosphatase2A (PP2A) (Tang et al. 2011). Further protein-DNA binding experiments have demonstrated that BZR1 can both bind the $5^{\prime}-\mathrm{CGTG}(\mathrm{T} / \mathrm{C}) \mathrm{G}-3^{\prime}$ elements (BRRE) and 5'-CANNTG-3' (E-box) of their target genes, with a preference for BRRE (He et al. 2002; Yin et al. 2002; Sun et al. 2010). Warm temperatures promote the formation of a PIF4-BRI1 EMS SUPPRESSOR 1 (BES1) complex to activate the expression of rate-limiting BR biosynthetic genes (Martinez et al. 2018) (Table 1). 
Table 1 Regulation of phytohormone biosynthesis and catabolism by warm temperatures

\begin{tabular}{|c|c|c|c|c|c|c|}
\hline Phytohormone & Locus & Name & Enzyme activity & Expression & Regulator & Reference \\
\hline \multirow[t]{3}{*}{ Auxin biosynthesis } & At4g28720 & YUC8 & Indole-3-pyruvate monooxygenase & up & PIF4 & (Sun et al. 2012) \\
\hline & At4g39950 & CYP79B2 & Tryptophan N-monooxygenase & up & PIF4 & (Franklin et al. 2011) \\
\hline & At1g70560 & TAA1 & Tryptophan aminotransferase & up & PIF4 & (Franklin et al. 2011) \\
\hline \multirow[t]{2}{*}{ GA biosynthesis } & At4g25420 & GA200X1 & Gibberellin 20 oxidase & up & TCP15 & (Ferrero et al. 2019) \\
\hline & At1g15550 & GA3OX1 & Gibberellin 3 oxidase & up & unknown & (Stavang et al. 2009) \\
\hline GA inactivation & At1g78440 & GA2OX1 & Gibberellin 2 oxidase & down & unknown & (Stavang et al. 2009) \\
\hline \multirow[t]{3}{*}{ BR biosynthesis } & At5g05690 & CPD/CYP90A1 & Steroid C-23 hydroxylase & up & PIF4-BES1 & (Martinez et al. 2018) \\
\hline & At3g50660 & DWF4/CYP90B1 & Steroid C-22 hydroxylase & up & PIF4-BES1 & (Martinez et al. 2018) \\
\hline & At3g30180 & BR6OX2 & Brassinosteroid-6-oxidase & up & PIF4-BES1 & (Martinez et al. 2018) \\
\hline \multirow[t]{4}{*}{ JA inactivation } & At3g11180 & JOX1 & Jasmonic acid oxidase & up & unknown & Zhu et al., 2021 \\
\hline & At5g05600 & JOX2 & Jasmonic acid oxidase & up & unknown & Zhu et al., 2021 \\
\hline & At3g55970 & J0X3 & Jasmonic acid oxidase & up & unknown & Zhu et al., 2021 \\
\hline & At5g07101 & ST2A & Sulfotransferase & up & PIF4 & (Ding et al. 2018) \\
\hline
\end{tabular}

In the normal growth temperature environment, the BR content in plants is relatively low, BZR1 is phosphorylated and inactivated by the cytoplasmic glycogen synthase kinase 3 (GSK3)-like protein kinase BRASSINOSTEROID INSENSITIVE2 (BIN2) (Li and Nam 2002; He et al. 2002; Yin et al. 2002) (Fig. 2). Under warm temperature, $\mathrm{BR}$ is accumulated, which inactivates
BIN2 by a Ser/Thr phosphatase bri1-SUPPRESSOR1 (BSU1) (Kim et al. 2009), leading to dephosphorylation of BZR1. The dephosphorylated BZR1 regulates gene expression and promotes thermoresponsive hypocotyl elongation. Surprisingly, genome-wide identification of BZR1 and PIF4 binding sites revealed that these two transcription factors share thousands of target genes

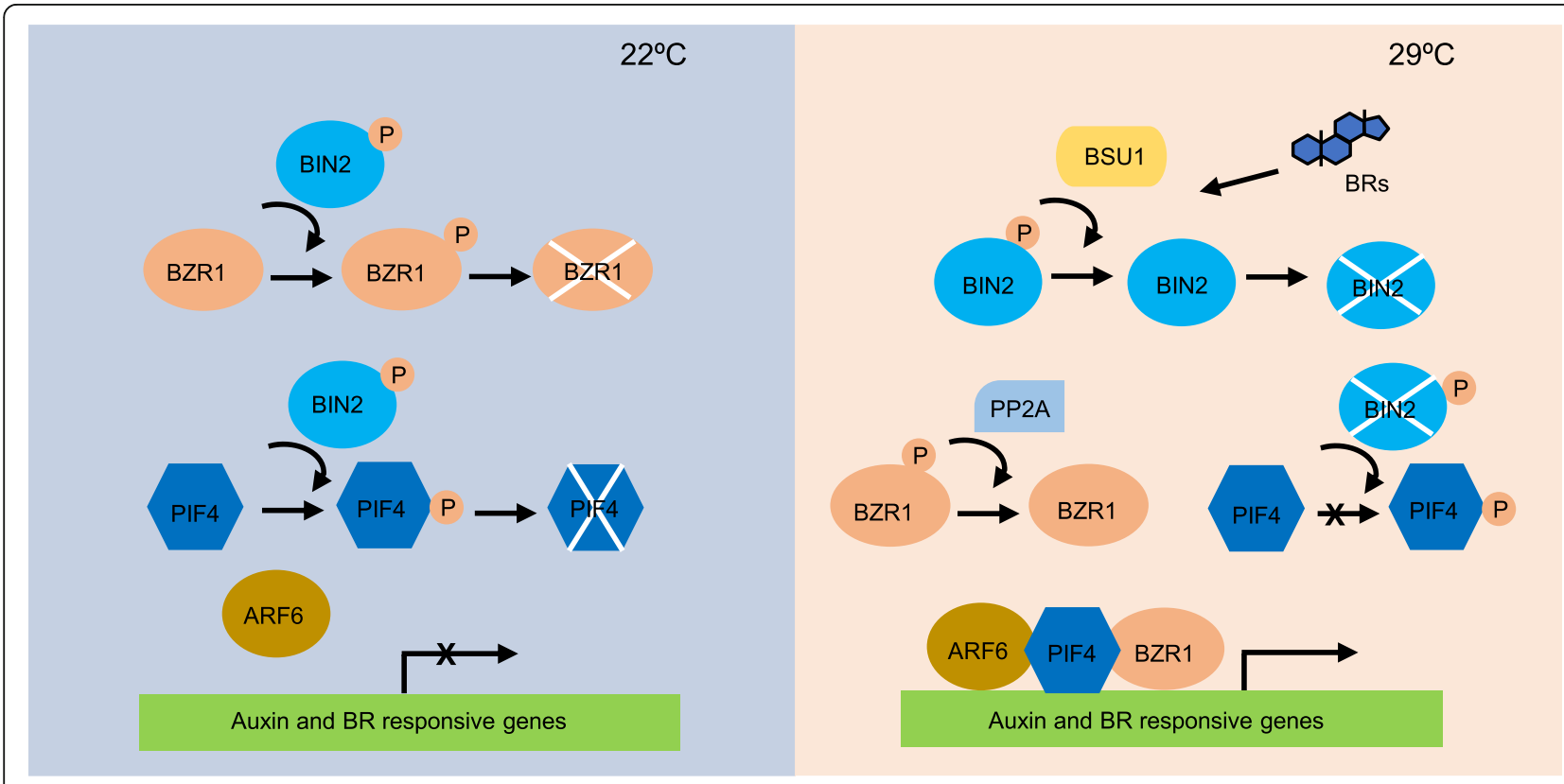

Fig. 2 Regulation of plant thermomorphogenesis by the BR signaling pathway. Under ambient temperature $\left(22^{\circ} \mathrm{C}\right)$ conditions, when $B R$ content is low, BZR1 and PIF4 are phosphorylated and inactivated by BIN2. Under warm temperature conditions $\left(29^{\circ} \mathrm{C}\right)$, the phosphatase BSU1 dephosphorylates and inactivates BIN2 when BR signal is perceived, releasing the inhibitory effect of BIN2 on PIF4. Meanwhile, BZR1 is dephosphorylated and activated by a group of PP2A. PIF4 regulates downstream genes for promoting hypocotyl elongation. BZR1 and ARF6 further enhance the transcription activation activity of PIF4 by interacting with PIF4. ARF6, AUXIN RESPONSE FACTOR 6; BIN2, BRASSINOSTEROID INSENSITIVE2; BSU1, briT-SUPPRESSOR1; BRs, brassinosteroids; BZR1, BRASSINAZOLE-RESISTANT 1; PIF4, phytochrome interacting factor 4; PP2A; protein phosphatase $2 \mathrm{~A}$ 
(Oh et al. 2012). BZR1 and PIF4 cooperatively regulate the expression of co-target genes, including genes involved in cell elongation (Oh et al. 2012). Consistent with their interdependency on the regulation of target gene expression, both BZR1 and PIF4 are required for hypocotyl elongation in warm temperatures (Oh et al. 2012). BZR1 also induces the expression of PIF4 and other growth promoting genes at elevated temperature in a feedback loop of auxin signaling (Ibanez et al. 2018). In addition to BZR1, the BR-regulated kinase, BIN2, also interacts with and inactivates PIF4 (Bernardo-Garcia et al. 2014). BIN2 phosphorylates PIF4 as well as BZR1, and this phosphorylation marks PIF4 for proteasomemediated degradation, thereby reducing cellular PIF4 levels (Fig. 2). At the molecular level, auxin and BR regulate the expression of common target genes, which is mediated by a direct interaction between AUXIN RESPONSE FACTOR 6 (ARF6) and BZR1 (Oh et al. 2012). ARF6 also interacts with PIF4, the interactions with BZR1 and PIF4 increase ARF6 activity by enhancing its binding to target promoters (Oh et al. 2014).

\section{GAs and thermomorphogenesis}

GAs are derived from diterpenoids and perceived by a soluble receptor, GIBBERELLIN INSENSITIVE DWARF 1 (GID1), which was originally identified from rice (Oryza sativa) and has three redundantly acting homologs GID1A, GID1B, and GID1C in Arabidopsis (Nakajima et al. 2006; Ueguchi-Tanaka et al. 2005). The current model suggests that GA-binding to GID1 receptor leads to conformation changes and nuclear localization of the receptors, which promotes their interaction with the DELLA proteins, targeting DELLA proteins for degradation by the ubiquitin-proteasome pathway mediated by the SLEEPY1 (SLY1) F-box protein (McGinnis et al. 2003; Griffiths et al. 2006; Dill et al. 2004; Willige et al. 2007). DELLAs, including GIBBERELLIC ACID INSENSITIVE (GAI), REPRESSOR OF ga1-3 (RGA), RGA-like 1 (RGL1), RGL2, and RGL3, are transcriptional regulators that restrict plant growth presumably by causing transcriptional reprogramming (Sun 2011). Therefore, GA promotes plant growth by means of removing the inhibitory DELLA proteins.

Previous studies demonstrated that GA is required for temperature-mediated hypocotyl elongation (Stavang et al. 2009), and the lack of the DELLA protein SLN1 in barley largely overcomes the inhibition of growth imposed by low temperature ( $\mathrm{Fu}$ et al. 2002), suggesting that the DELLA proteins can be an important regulator of thermomorphogenesis (Fig. 3). The class I TEOSINTE BRANCHED 1, CYCLOIDEA, PCF (TCP) transcription factors TCP14 and TCP15 control the levels of the DELLA protein RGA, and the expression of growthrelated genes in response to an increase in temperature (Ferrero et al. 2019). TCP15 directly targets the gibberellin biosynthesis gene GA20ox1 to promote cell expansion at warm temperature (Ferrero et al. 2019) (Table 1). TCP5, TCP13, and TCP17 promote PIF4 activity at both transcriptional and post-transcriptional levels under warm temperature conditions (Zhou et al. 2019; Han

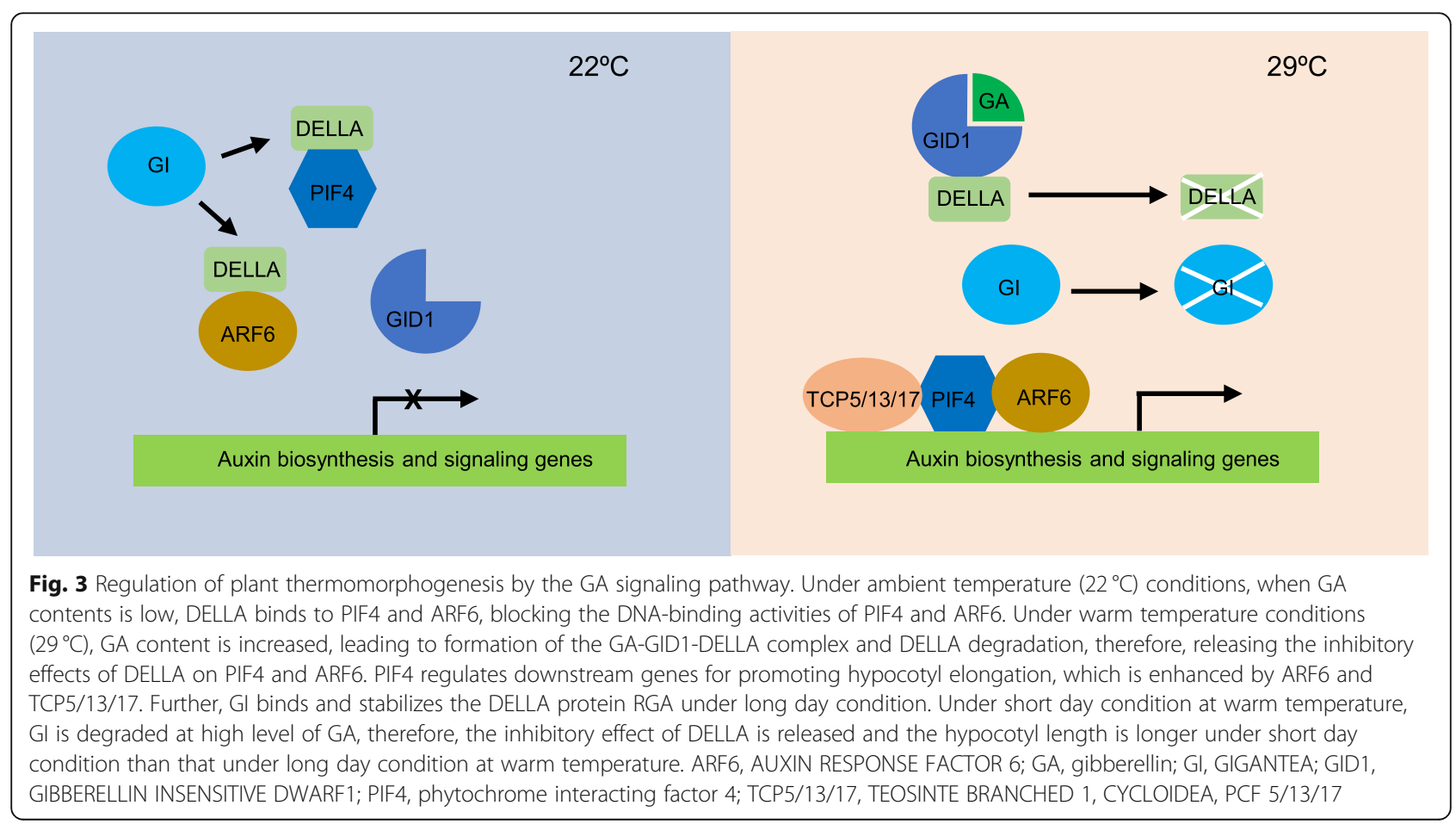


et al. 2019). DELLAs interact with PIF4, preventing PIF4 from binding to its target promoters, thereby inactivating PIF4 (Feng et al. 2008; Li et al. 2016; Daviere and Achard 2016). Warm temperatures enhance accumulation of the chaperone GIGANTEA (GI), and GI stabilizes the DELLA protein RGA under long day conditions, thereby attenuating PIF4-mediated thermomorphogenesis (Park et al. 2020). In contrast, under short days, GI accumulation is reduced and RGA is readily degraded through the GA signaling pathway, promoting thermomorphogenic growth (Park et al. 2020). In addition, DELLAs also interact with and inactivate ARF6 to fine-tune plant growth under warm temperature conditions (Oh et al. 2014).

\section{Ethylene and thermomorphogenesis}

Ethylene, a gas hormone synthesized by plants, is widely involved in seed germination, growth, development, and biological and abiotic stress responses (Dubois et al. 2018). Ethylene-mediated hypocotyl growth is contingent on temperature contexts in that ethylene promotes hypocotyl growth at $22^{\circ} \mathrm{C}$ but represses it at $28^{\circ} \mathrm{C}$ (Fig. 4) (Jin et al. 2018; Kim et al. 2021). Ethylene suppresses hypocotyl growth during skotomorphogenesis, which is mediated by several ethylene-responsive regulators (Sun et al. 2015). Notably, these regulators are involved in the ethylene mediated repression of hypocotyl growth under warm environment (Kim et al.
2021). ERF95 and ERF97 are two ethylene-responsive factors, which are directly regulated by ethylene insensitive 3 (EIN3). Warm temperatures induce the degradation of negative regulators EIN3-binding F-box protein $1 / 2(E B F 1 / 2)$ via the E3 ubiquitin ligase saltand drought-induced ring finger 1 (SIDR1), therefore leading to more ethylene responses and inhibition of hypocotyl growth (Hao et al. 2021) (Fig. 4). Auxin biosynthesis is stimulated by PIF4 and the thermoresponsive PIF4-mediated pathways reinforce the induction of thermomorphogenic growth (Franklin et al. 2011). The ethylene-mediated repression of hypocotyl thermomorphogenesis is compromised in PIF4-deficient mutants, suggesting that PIF4 is critical for the reversed action of ethylene under warm temperature conditions. It is known that auxin effects on hypocotyl growth is exerted by cell elongation through SAUR19 (Spartz et al. 2014). Chromatin immunoprecipitation assays revealed that EIN3 directly binds to promoter of Arabidopsis PP2C Clade D7 (APD7), encoding a phosphatase that inhibits $\mathrm{H}(+)$-ATPases (Chang et al. 2013) (Fig. 4). At $22^{\circ} \mathrm{C}$, auxin level is relatively low, and thus ethylene promotes hypocotyl growth through the PIF3 pathway (Ma et al. 2018). In contrast, under warm temperature conditions, when auxin is highly accumulated via the PIF4-mediated pathway, the repressive action of the EIN3-APD7 module on the auxin-induced hypocotyl cell expansion is more evident (Kim et al. 2021).

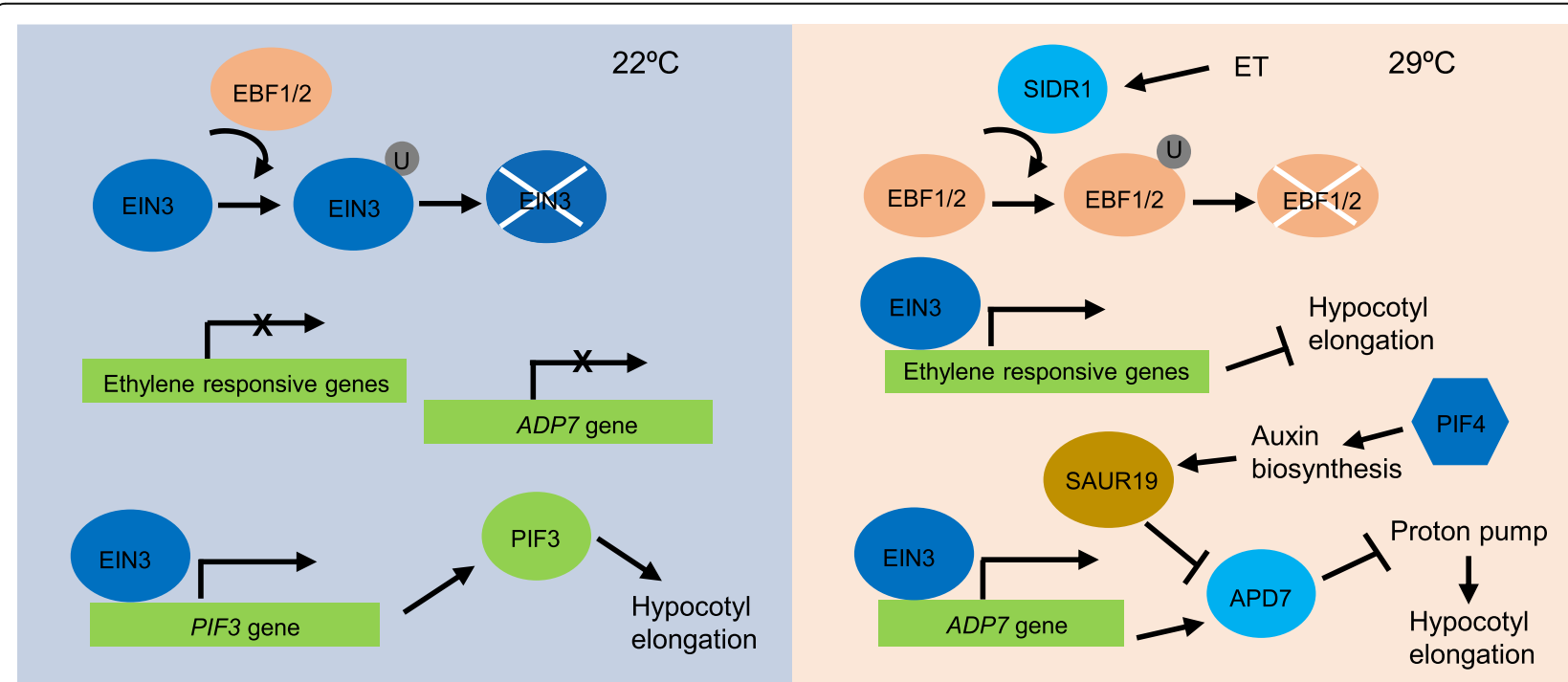

Fig. 4 Regulation of plant thermomorphogenesis by the ethylene signaling pathway. Under ambient temperature $\left(22^{\circ} \mathrm{C}\right)$ conditions, when ET contents is low, EIN3 is subjected to EBF1/2-mediated degradation. Low level of EIN3 induces the expression of PIF3, enabling hypocotyl growth. Under warm temperature conditions $\left(29^{\circ} \mathrm{C}\right), \mathrm{EBF} 1 / 2$ is ubiquitinated and degraded by SIDR1, releasing the inhibitory effects of EBF1/2 on EIN3. EIN3 upregulates ethylene responsive genes to inhibit hypocotyl growth. EIN3 also upregulates the expression of APD7, and APD7 represses the proton pump activity, therefore inhibiting cell expansion. On the other hand, PIF4-mediated auxin signaling represses APD7 activity through SAUR19 to promote hypocotyl elongation. APD7, Arabidopsis PP2C Clade D7; EBF1/2, EIN3-binding F-box protein 1/2; EIN3, ethylene insensitive 3; ET, ethylene; PIF3/4, phytochrome interacting factor 3/4; SIDR1, salt- and drought-induced ring finger 1 


\section{$\mathrm{JA}$ and thermomorphogenesis}

The jasmonates (JAs), including jasmonic acid and its derivatives, and salicylic acid (SA) are two important plant hormones modulating inducible defenses (Thaler et al. 2012). JA biosynthesis and its signaling pathway have been well characterized (Howe et al. 2018). JAs are synthesized from $\alpha$-linolenic acid ( $\alpha$-LeA/18:3) via the octadecanoid pathway, and converted to the bioactive type JA-Isoleucine (JA-Ile), which is regulated by JAR1 (Jasmonate resistant 1) (Huang et al. 2017). In the JA metabolism pathway, three ER localized cytochrome P450 CYP94 family oxidases generate the JA derivatives 12-hydroxy JA-Ile (12OH-JA-Ile), which further forms the 12-hydroxy JA (12OD-JA) after cleaving the Ile group by amido-hydrolases IAR3 and ILL6 (Wasternack and Feussner 2018). Jasmonate-induced oxygenase (JOX)/Jasmonic acid oxidase (JAO) can catalyze the oxidation of JA to 12OH-JA (Heitz et al. 2019; Caarls et al. 2017). Subsequently, $12 \mathrm{OH}-J \mathrm{~A}$ can be sulfated by the sulfotransferase ST2A to form 12-hydroxy jasmonoyl sulfate (12 $\mathrm{HSO}_{4}$-JA) (Fernandez-Milmanda et al. 2020). JA-Ile is perceived by the receptor complex containing COI1 (Coronatine insensitive 1) and JAZ (Jasmonate ZIM-Domain). The JAZ proteins inhibit transcript factors, such as MYC2, and are subjected to $26 \mathrm{~S}$ proteasome-mediated degradation after JA treatment (Howe et al. 2018).

Recently, Zhu et al. reported that warm temperaturetriggered hypocotyl elongation was largely repressed by MeJA treatment at $28^{\circ} \mathrm{C}$ in a concentration-dependent manner in Arabidopsis and wheat (Zhu et al. 2021). Furthermore, the expression of JOXS and ST2A, genes encoding enzymes involved in the regulation catabolic processes leading to $12 \mathrm{HSO} 4-\mathrm{JA}$, was significantly upregulated at warm temperatures (Table 1). In contrast, the Arabidopsis JA deficient allene oxide synthase (aos) mutant displays a slight longer hypocotyl compared with wild type (Zhu et al. 2021). Therefore, JA content is negatively related to hypocotyl elongation at warm temperatures.

\section{Conclusion remarks and future perspectives}

Plants in nature experience a wide range of daily environmental temperatures. Global warming of $1.5^{\circ} \mathrm{C}$ and $2{ }^{\circ} \mathrm{C}$ will be exceeded during the twenty-first century unless deep reductions in carbon dioxide $(\mathrm{CO} 2)$ and other greenhouse gas emissions occur in the coming decades (IPCC, 2021). As a consequence, worldwide cereal production is estimated to have a loss of $6-7 \%$ per $1{ }^{\circ} \mathrm{C}$ increase in average seasonal temperature and associated extreme temperature conditions (Lesk et al. 2016). A further understanding on how plants perceive and respond to warm temperature is important for designing resilient crops with climate changes in future. However, most of the current research was done with the model plant Arabidopsis. Since different species may have different harmonized growth temperature (Lam Dai et al. 2018; Zhao et al. 2017; Peng et al. 2004), therefore, more work on other crops such as rice, wheat, soybean, should be carried out in future. There are natural variations in ELF3 in thermomorphogenic responses in Arabidopsis (Raschke et al., 2015). Identification of natural variations in key thermo-regulators in crop plants may help to develop temperature resilient crops through markerassisted breeding.

Warm temperatures promote growth and accelerate flowering, which helps plants to escape quickly from the soil surface with higher temperature and complete their lifecycle in time (Casal and Balasubramanian 2019). Several thermosensors have been uncovered in plants. Although temperature signals should be quite different from chemical signals, whether there are also membrane-localized thermosensors existed in plants is an open question. Previous studies have shown that phytohormones such as auxin, GAs, BR and ethylene are important for promoting plant growth (Casal and Balasubramanian 2019; Nieto et al. 2015), while JAs inhibit plant growth under warm temperature conditions (Zhu et al. 2021). However, whether other phytohormones are also involved in thermomorphogenesis is not yet reported. ABA-INSENSITIVE3 (ABI3), ABI5, and DELLAs positively activated the expression of SOMNUS (SOM) and other high-temperature-inducible genes to inhibit seed germination (Lim et al. 2013). A recent study showed that ABA interacts synergistically with $\mathrm{BR}$ to regulate plant growth and adaptation (Li et al. 2021). These results suggest that it is possible that ABA may also regulate plant growth under warm temperature conditions.

The crosstalk between different plant hormones in plant growth has been reported, either synergistically or antagonistically (Depuydt and Hardtke 2011). The biosynthetic and signaling pathways of auxin and BR are interconnected during thermomorphogenesis (Martinez et al. 2018; Ibanez et al. 2018), whether other plant hormones also have crosstalks under warm temperature conditions awaits future investigation.

\section{Authors' contributions}

H.P.L, M.J.W., J.J.W, and J.X.L wrote the paper. All authors read and approved the final manuscript.

\section{Funding}

This project was supported by the National Natural Science Foundation of China (31872653 and 32000374) and the Fundamental Research Funds for the Zhejiang Provincial Universities (2021XZZX023).

Availability of data and materials Not applicable. 


\section{Declaration}

Ethics approval and consent to participate

Not applicable.

\section{Consent for publication}

Not applicable.

\section{Competing interests}

J.X.L is a member of the editorial board, but was not involved in the journal's review or any decisions related to this submission.

\section{Received: 6 October 2021 Accepted: 1 December 2021}

\section{Published online: 18 December 2021}

\section{References}

Bellstaedt J, Trenner J, Lippmann R, Poeschl Y, Zhang XX, Friml J, Quint M, Delker C (2019) A mobile auxin signal connects temperature sensing in cotyledons with growth responses in hypocotyls. Plant Physiol 180(2):757-766. https:// doi.org/10.1104/pp.18.01377

Bernardo-Garcia S, de Lucas M, Martinez C, Espinosa-Ruiz A, Daviere JM, Prat S (2014) BR-dependent phosphorylation modulates PIF4 transcriptional activity and shapes diurnal hypocotyl growth. Genes Dev 28(15):1681-1694. https:// doi.org/10.1101/gad.243675.114

Binder BM (2020) Ethylene signaling in plants. J Biol Chem 295(22):7710-7725. https://doi.org/10.1074/jbc.REV120.010854

Burger M, Chory J (2020) The many models of strigolactone signaling. Trends Plant Sci 25(4):395-405. https://doi.org/10.1016/j.tplants.2019.12.009

Burgie ES, Vierstra RD (2014) Phytochromes: An atomic perspective on photoactivation and signaling. Plant Cell 26(12):4568-4583. https://doi.org/1 $0.1105 /$ tpc. 114.131623

Caarls L, Elberse J, Awwanah M, Ludwig NR, de Vries M, Zeilmaker T, Van Wees SCM, Schuurink RC, Van den Ackerveken G (2017) Arabidopsis JASMONATEINDUCED OXYGENASES down-regulate plant immunity by hydroxylation and inactivation of the hormone jasmonic acid. Proc Natl Acad Sci U S A 114(24): 6388-6393. https://doi.org/10.1073/pnas.1701101114

Casal JJ, Balasubramanian S (2019) Thermomorphogenesis. Annu Rev Plant Biol 70(1):321-346. https://doi.org/10.1146/annurev-arplant-050718-095919

Chang KN, Zhong S, Weirauch MT, Hon G, Pelizzola M, Li H, Huang SC, Schmitz RJ, Urich MA, Kuo D, Nery JR, Qiao H, Yang A, Jamali A, Chen H, Ideker T, Ren B, Bar-Joseph Z, Hughes TR, Ecker JR (2013) Temporal transcriptional response to ethylene gas drives growth hormone cross-regulation in Arabidopsis. eLife 2. https://doi.org/10.7554/eLife.00675

Chen K, Li GJ, Bressan RA, Song CP, Zhu JK, Zhao Y (2020) Abscisic acid dynamics, signaling, and functions in plants. J Integr Plant Biol 62(1):25-54. https://doi.org/10.1111/jipb.12899

Chung BYW, Balcerowicz M, Di Antonio M, Jaeger KE, Geng F, Franaszek K, Marriott P, Brierley I, Firth AE, Wigge PA (2020) An RNA thermoswitch regulates daytime growth in Arabidopsis. Nat Plant 6(5):522-532. https://doi. org/10.1038/s41477-020-0633-3

Cortleven A, Leuendorf JE, Frank M, Pezzetta D, Bolt S, Schmulling T (2019) Cytokinin action in response to abiotic and biotic stresses in plants. Plant Cell Environ 42(3):998-1018. https://doi.org/10.1111/pce.13494

Daviere JM, Achard P (2016) A pivotal role of DELLAs in regulating multiple hormone signals. Mol Plant 9(1):10-20. https:/doi.org/10.1016/..molp.2015.09.011

Delker C, Sonntag L, James GV, Janitza P, Ibanez C, Ziermann H, Peterson T, Denk K, Mull S, Ziegler J, Davis SJ, Schneeberger K, Quint M (2014) The DET1COP1-HY5 pathway constitutes a multipurpose signaling module regulating plant photomorphogenesis and thermomorphogenesis. Cell Rep 9(6):19831989. https://doi.org/10.1016/j.celrep.2014.11.043

Depuydt S, Hardtke CS (2011) Hormone signalling crosstalk in plant growth regulation. Curr Biol 21(9):R365-R373. https://doi.org/10.1016/j.cub.2011.03.013

Dill A, Thomas SG, Hu JH, Steber CM, Sun TP (2004) The Arabidopsis F-box protein SLEEPY1 targets gibberellin signaling repressors for gibberellin-induced degradation. Plant Cell 16(6):1392-1405. https://doi.org/10.1105/tpc.020958

Ding L, Wang S, Song ZT, Jiang Y, Han JJ, Lu SJ, Li L, Liu JX (2018) Two B-box domain proteins, BBX18 and BBX23, interact with ELF3 and regulate thermomorphogenesis in Arabidopsis. Cell Rep 25(7):1718-1728. https://doi. org/10.1016/j.celrep.2018.10.060
Dubois M, Van den Broeck L, Inze D (2018) The pivotal role of ethylene in plant growth. Trends Plant Sci 23(4):311-323. https://doi.org/10.1016/j.tplants.2018. 01.003

Feng SH, Martinez C, Gusmaroli G, Wang Y, Zhou JL, Wang F, Chen LY, Yu L, Iglesias-Pedraz JM, Kircher S, Schafer E, Fu XD, Fan LM, Deng XW (2008) Coordinated regulation of Arabidopsis thaliana development by light and gibberellins. Nature 451(7177):475-479. https://doi.org/10.1038/nature06448

Fernandez-Milmanda GL, Crocco CD, Reichelt M, Mazza CA, Koellner TG, Zhang T, Cargnel MD, Lichy MZ, Fiorucci AS, Fankhauser C, Koo AJ, Austin AT, Gershenzon J, Ballare CL (2020) A light-dependent molecular link between competition cues and defence responses in plants. Nat Plant 6(3):223-230. https://doi.org/10.1038/s41477-020-0604-8

Ferrero LV, Viola IL, Ariel FD, Gonzalez DH (2019) Class I TCP transcription factors target the gibberellin biosynthesis gene GA200x1 and the growth-promoting genes HBII and PRE6 during thermomorphogenic growth in Arabidopsis. Plant Cell Physiol 60(8):1633-1645. https://doi.org/10.1093/pcp/pcz137

Fiorucci AS, Galvao VC, Ince YC, Boccaccini A, Goyal A, Allenbach Petrolati L, Trevisan M, Fankhauser C (2020) PHYTOCHROME INTERACTING FACTOR 7 is important for early responses to elevated temperature in Arabidopsis seedlings. New Phytol 226(1):50-58. https://doi.org/10.1111/nph.16316

Franklin KA, Lee SH, Patel D, Kumar SV, Spartz AK, Gu C, Ye S, Yu P, Breen G, Cohen JD, Wigge PA, Gray WM (2011) PHYTOCHROME-INTERACTING FACTOR 4 (PIF4) regulates auxin biosynthesis at high temperature. Proc Natl Acad Sci U S A 108(50):20231-20235. https://doi.org/10.1073/pnas.1110682108

Fu XD, Richards DE, Ait-Ali T, Hynes LW, Ougham H, Peng JR, Harberd NP (2002) Gibberellin-mediated proteasome-dependent degradation of the barley DELLA protein SLN1 repressor. Plant Cell 14(12):3191-3200. https://doi.org/1 0.1105/tpc.006197

Gangappa SN, Kumar SV (2017) DET1 and HY5 control PIF4-mediated thermosensory elongation growth through distinct mechanisms. Cell Rep 18(2):344-351. https://doi.org/10.1016/j.celrep.2016.12.046

Gray WM, Ostin A, Sandberg G, Romano CP, Estelle M (1998) High temperature promotes auxin-mediated hypocotyl elongation in Arabidopsis. Proc Natl Acad Sci U S A 95(12):7197-7202. https://doi.org/10.1073/pnas.95.12.7197

Griffiths J, Murase K, Rieu I, Zentella R, Zhang ZL, Powers SJ, Gong F, Phillips AL, Hedden P, Sun TP, Thomas SG (2006) Genetic characterization and functional analysis of the GID1 gibberellin receptors in Arabidopsis. Plant Cell 18(12): 3399-3414. https://doi.org/10.1105/tpc.106.047415

Hahm J, Kim K, Qiu Y, Chen M (2020) Increasing ambient temperature progressively disassembles Arabidopsis phytochrome B from individual photobodies with distinct thermostabilities. Nat Commun 11(1):1660. https:// doi.org/10.1038/s41467-020-15526-Z

Han X, Yu H, Yuan R, Yang Y, An F, Qin G (2019) Arabidopsis transcription factor TCP5 controls plant thermomorphogenesis by positively regulating PIF4 activity. iScience 15:611-622. https://doi.org/10.1016/j. isci.2019.04.005

Hanzawa T, Shibasaki K, Numata T, Kawamura Y, Gaude T, Rahman A (2013) Cellular auxin homeostasis under high temperature is regulated through a SORTING NEXIN1-dependent endosomal trafficking pathway. Plant Cell 25(9): 3424-3433. https://doi.org/10.1105/tpc.113.115881

Hao DD, Jin L, Wen X, Yu FF, Xie Q, Guo HW (2021) The RING E3 ligase SDIR1 destabilizes EBF1/EBF2 and modulates the ethylene response to ambient temperature fluctuations in Arabidopsis. Proc Natl Acad Sci U S A 118(6): e2024592118. https://doi.org/10.1073/pnas.2024592118

He JX, Gendron JM, Yang YL, Li JM, Wang ZY (2002) The GSK3-like kinase BIN2 phosphorylates and destabilizes BZR1, a positive regulator of the brassinosteroid signaling pathway in Arabidopsis. Proc Natl Acad Sci U S A 99(15):10185-10190. https://doi.org/10.1073/pnas.152342599

Heitz T, Smirnova E, Marquis V, Poirier L (2019) Metabolic control within the jasmonate biochemical pathway. Plant Cell Physiol 60(12):2621-2628. https:// doi.org/10.1093/pcp/pcz172

Howe GA, Major IT, Koo AJ (2018) Modularity in jasmonate signaling for multistress resilience. Annu Rev Plant Biol 69(1):387-415. https://doi.org/1 0.1146/annurev-arplant-042817-040047

Huang H, Liu B, Liu LY, Song SS (2017) Jasmonate action in plant growth and development. J Exp Bot 68(6):1349-1359. https://doi.org/10.1093/jxb/erw495

Ibanez C, Delker C, Martinez C, Buerstenbinder K, Janitza P, Lippmann R, Ludwig W, Sun H, James GV, Klecker M, Grossjohann A, Schneeberger K, Prat S, Quint M (2018) Brassinosteroids dominate hormonal regulation of plant thermomorphogenesis via BZR1. Curr Biol 28(2):303-310. https://doi.org/10.1 016/j.cub.2017.11.077 
Jin H, Pang L, Fang S, Chu J, Li R, Zhu Z (2018) High ambient temperature antagonizes ethylene-induced exaggerated apical hook formation in etiolated Arabidopsis seedlings. Plant Cell Environ 41(12):2858-2868. https:// doi.org/10.1111/pce.13417

Jung JH, Barbosa AD, Hutin S, Kumita JR, Gao M, Derwort D, Silva CS, Lai X, Pierre E, Geng F, Kim SB, Baek S, Zubieta C, Jaeger KE, Wigge PA (2020) A prion-like domain in ELF3 functions as a thermosensor inArabidopsis. Nature 585(7824): 256-260. https://doi.org/10.1038/s41586-020-2644-7

Jung JH, Domijan M, Klose C, Biswas S, Ezer D, Gao M, Khattak AK, Box MS, Charoensawan V, Cortijo S, Kumar M, Grant A, Locke JCW, Schaefer E, Jaeger KE, Wigge PA (2016) Phytochromes function as thermosensors in Arabidopsis. Science 354(6314):886-889. https://doi.org/10.1126/science.aaf6005

Kim JY, Park YJ, Lee JH, Kim ZH, Park CM (2021) EIN3-mediated ethylene signaling attenuates auxin response during hypocotyl thermomorphogenesis. Plant Cell Physiol 62(4):708-720. https://doi.org/10.1093/pcp/pcab028

Kim S, Hwang G, Kim S, Thom Nguyen T, Kim H, Jeong J, Kim J, Kim J, Choi G, Oh E (2020) The epidermis coordinates thermoresponsive growth through the phyB-PIF4-auxin pathway. Nat Commun 11(1):1053. https://doi.org/10.1038/ s41467-020-14905-w

Kim TW, Guan S, Sun Y, Deng Z, Tang W, Shang JX, Sun Y, Burlingame AL, Wang ZY (2009) Brassinosteroid signal transduction from cell-surface receptor kinases to nuclear transcription factors. Nat Cell Biol 11(10):1254-U1233. https://doi.org/10.1038/ncb1970

Klose C, Nagy F, Schaefer E (2020) Thermal reversion of plant phytochromes. Mol Plant 13(3):386-397. https://doi.org/10.1016/j.molp.2019.12.004

Kumar SV, Lucyshyn D, Jaeger KE, Alos E, Alvey E, Harberd NP, Wigge PA (2012) Transcription factor PIF4 controls the thermosensory activation of flowering Nature 484(7393):242-245. https://doi.org/10.1038/nature10928

Kunihiro A, Yamashino T, Nakamichi N, Niwa Y, Nakanishi H, Mizuno T (2011) PHYTOCHROME-INTERACTING FACTOR 4 and 5 (PIF4 and PIF5) activate the homeobox ATHB2 and auxin-inducible IAA29 genes in the coincidence mechanism underlying photoperiodic control of plant growth of Arabidopsis thaliana. Plant Cell Physiol 52(8):1315-1329. https://doi.org/10.1093/pcp/ pcr076

Lam Dai V, Zhu T, Verstraeten I, van de Cotte B, Gevaert K, De Smet I, Int Wheat Genome S (2018) Temperature-induced changes in the wheat phosphoproteome reveal temperature-regulated interconversion of phosphoforms. J Exp Bot 69(19):4609-4624. https://doi.org/10.1093/jxb/ery204

Legris M, Klose C, Burgie ES, Rojas CC, Neme M, Hiltbrunner A, Wigge PA, Schafer E, Vierstra RD, Casal JJ (2016) Phytochrome B integrates light and temperature signals in Arabidopsis. Science 354(6314):897-900. https://doi. org/10.1126/science.aaf5656

Legris M, Nieto C, Sellaro R, Prat S, Casal JJ (2017) Perception and signalling of light and temperature cues in plants. Plant J 90(4):683-697. https://doi.org/1 0.1111/tpj.13467

Lesk C, Rowhani P, Ramankutty N (2016) Influence of extreme weather disasters on global crop production. Nature 529(7584):84-87. https://doi.org/10.1038/ nature16467

Li JM, Nam KH (2002) Regulation of brassinosteroid signaling by a GSK3/SHAGGYlike kinase. Science 295(5558):1299-1301. https:/doi.org/10.1126/science.1065769

Li KL, Yu RB, Fan LM, Wei N, Chen HD, Deng XW (2016) DELLA-mediated PIF degradation contributes to coordination of light and gibberellin signalling in Arabidopsis. Nat Commun 7(1):11868. https://doi.org/10.1038/ncomms11868

Li Q, Xu F, Chen Z, Teng Z, Sun K, Li X, Yu J, Zhang G, Liang Y, Huang X, Du L, Qian Y, Wang Y, Chu C, Tang J (2021) Synergistic interplay of ABA and BR signal in regulating plant growth and adaptation. Nat Plant 7(8):1108-1118. https://doi.org/10.1038/s41477-021-00959-1

Lim S, Park J, Lee N, Jeong J, Toh S, Watanabe A, Kim J, Kang H, Kim DH, Kawakami N, Choi G (2013) ABA-INSENSITIVE3, ABA-INSENSITIVE5, and DELLAs interact to activate the expression of SOMNUS and other high-temperatureinducible genes in imbibed seeds in Arabidopsis. Plant Cell 25(12):48634878. https://doi.org/10.1105/tpc.113.118604

Ma Q, Wang X, Sun J, Mao T (2018) Coordinated regulation of hypocotyl cell elongation by light and ethylene through a microtubule destabilizing protein. Plant Physiol 176(1):678-690. https://doi.org/10.1104/pp.17.01109

Martinez C, Espinosa-Ruiz A, de Lucas M, Bernardo-Garcia S, Franco-Zorrilla JM, Prat S (2018) PIF4-induced BR synthesis is critical to diurnal and thermomorphogenic growth. EMBO J 37(23):e99552. https://doi.org/10.152 52/embj.201899552

McGinnis KM, Thomas SG, Soule JD, Strader LC, Zale JM, Sun TP, Steber CM (2003) The Arabidopsis SLEEPY1 gene encodes a putative F-box subunit of an
SCF E3 ubiquitin ligase. Plant Cell 15(5):1120-1130. https://doi.org/10.1105/ tpc.010827

Nakajima M, Shimada A, Takashi Y, Kim YC, Park SH, Ueguchi-Tanaka M, Suzuki H, Katoh E, luchi S, Kobayashi M, Maeda T, Matsuoka M, Yamaguchi I (2006) Identification and characterization of Arabidopsis gibberellin receptors. Plant J 46(5):880-889. https://doi.org/10.1111/j.1365-313X.2006.02748.x

Nicotra AB, Atkin OK, Bonser SP, Davidson AM, Finnegan EJ, Mathesius U, Poot $P$, Purugganan MD, Richards CL, Valladares F, van Kleunen M (2010) Plant phenotypic plasticity in a changing climate. Trends Plant Sci 15(12):684-692. https://doi.org/10.1016/j.tplants.2010.09.008

Nieto C, Lopez-Salmeron V, Daviere JM, Prat S (2015) ELF3-PIF4 interaction regulates plant growth independently of the evening complex. Curr Biol 25(2):187-193. https://doi.org/10.1016/j.cub.2014.10.070

Nozue K, Covington MF, Duek PD, Lorrain S, Fankhauser C, Harmer SL, Maloof JN (2007) Rhythmic growth explained by coincidence between internal and external cues. Nature 448(7151):358-361. https://doi.org/10.1038/nature05946

Nusinow DA, Helfer A, Hamilton EE, King JJ, Imaizumi T, Schultz TF, Farre EM, Kay SA (2011) The ELF4-ELF3-LUX complex links the circadian clock to diurnal control of hypocotyl growth. Nature 475(7356):398-402. https://doi.org/10.1 038/nature10182

Oh E, Zhu JY, Bai MY, Arenhart RA, Sun Y, Wang ZY (2014) Cell elongation is regulated through a central circuit of interacting transcription factors in the Arabidopsis hypocotyl. eLife:3. https://doi.org/10.7554/eLife.03031

Oh E, Zhu JY, Wang ZY (2012) Interaction between BZR1 and PIF4 integrates brassinosteroid and environmental responses. Nat Cell Biol 14(8):802-809. https://doi.org/10.1038/ncb2545

Park YJ, Kim JY, Lee JH, Lee BD, Paek NC, Park CM (2020) GIGANTEA shapes the photoperiodic rhythms of thermomorphogenic growth in Arabidopsis. Mol Plant 13(3):459-470. https://doi.org/10.1016/j.molp.2020.01.003

Park YJ, Lee HJ, Ha JH, Kim JY, Park CM (2017) COP1 conveys warm temperature information to hypocotyl thermomorphogenesis. New Phytol 215(1):269-280. https://doi.org/10.1111/nph.14581

Peng SB, Huang JL, Sheehy JE, Laza RC, Visperas RM, Zhong XH, Centeno GS, Khush GS, Cassman KG (2004) Rice yields decline with higher night temperature from global warming. Proc Natl Acad Sci U S A 101(27):99719975. https://doi.org/10.1073/pnas.0403720101

Peres A, Soares JS, Tavares RG, Righetto G, Zullo MAT, Mandava NB, Menossi M (2019) Brassinosteroids, the sixth class of phytohormones: a molecular view from the discovery to hormonal interactions in plant development and stress adaptation. Int J Mol Sci 20(2):33. https://doi.org/10.3390/ijms20020331

Quint M, Delker C, Franklin KA, Wigge PA, Halliday KJ, van Zanten M (2016) Molecular and genetic control of plant thermomorphogenesis. Nat Plant 2(1): 15190. https://doi.org/10.1038/nplants.2015.190

Raschke A, Ibanez C, Ullrich KK, Anwer MU, Becker S, Gloeckner A, Trenner J, Denk K, Saal B, Sun X, Ni M, Davis SJ, Delker C, Quint M (2015) Natural variants of ELF3 affect thermomorphogenesis by transcriptionally modulating PIF4-dependent auxin response genes. BMC Plant Biol 15(1):197. https://doi. org/10.1186/s12870-015-0566-6

Rathore S, Bindoff NL, Phillips HE, Feng M (2020) Recent hemispheric asymmetry in global ocean warming induced by climate change and internal variability. Nat Commun 11(1):2008. https://doi.org/10.1038/s41467-020-15754-3

Salehin M, Bagchi R, Estelle M (2015) SCFTIR1/AFB-based auxin perception: mechanism and role in plant growth and development. Plant Cell 27(1):9-19. https://doi.org/10.1105/tpc.114.133744

Schlenker W, Roberts MJ (2009) Nonlinear temperature effects indicate severe damages to US crop yields under climate change. Proc Natl Acad Sci U S A 106(37):15594-15598. https://doi.org/10.1073/pnas.0906865106

Shu K, Zhou W, Chen F, Luo X, Yang W (2018) Abscisic acid and gibberellins antagonistically mediate plant development and abiotic stress responses. Front Plant Sci 9:416. https://doi.org/10.3389/fpls.2018.00416

Spartz AK, Ren H, Park MY, Grandt KN, Lee SH, Murphy AS, Sussman MR, Overvoorde PJ, Gray WM (2014) SAUR inhibition of PP2C-D phosphatases activates plasma membrane H+-ATPases to promote cell expansion in Arabidopsis. Plant Cell 26(5):2129-2142. https://doi.org/10.1105/tpc.114.126037

Stavang JA, Gallego-Bartolome J, Gomez MD, Yoshida S, Asami T, Olsen JE, Garcia-Martinez JL, Alabadi D, Blazquez MA (2009) Hormonal regulation of temperature-induced growth in Arabidopsis. Plant J 60(4):589-601. https:// doi.org/10.1111/j.1365-313X.2009.03983.x

Sun J, Ma Q, Mao T (2015) Ethylene regulates the Arabidopsis microtubuleassociated protein WAVE-DAMPENED2-LIKE5 in etiolated hypocotyl elongation. Plant Physiol 169(1):325-337. https://doi.org/10.1104/pp.15.00609 
Sun J, Qi L, Li Y, Chu J, Li C (2012) PIF4-mediated activation of YUCCA8 expression integrates temperature into the auxin pathway in regulating Arabidopsis hypocotyl growth. PLoS Genet 8(3):e1002594. https://doi.org/1 0.1371/journal.pgen.1002594

Sun J, Tian Y, Lian Q, Liu JX (2020) Mutation of DELAYED GREENING1 impairs chloroplast RNA editing at elevated ambient temperature in Arabidopsis. J Genet Genom 47(4):201-212. https://doi.org/10.1016/j. jgg.2020.03.005

Sun TP (2011) The molecular mechanism and evolution of the GA-GID1-DELLA signaling module in plants. Curr Biol 21(9):R338-R345. https://doi.org/10.101 6/j.cub.2011.02.036

Sun Y, Fan XY, Cao DM, Tang W, He K, Zhu JY, He JX, Bai MY, Zhu S, Oh E, Patil S, Kim TW, Ji H, Wong WH, Rhee SY, Wang Y (2010) Integration of brassinosteroid signal transduction with the transcription network for plant growth regulation in Arabidopsis. Dev Cell 19(5):765-777. https://doi.org/10.1 016/j.devcel.2010.10.010

Tang W, Yuan M, Wang R, Yang Y, Wang C, Oses-Prieto JA, Kim TW, Zhou HW, Deng Z, Gampala SS, Gendron JM, Jonassen EM, Lillo C, DeLong A, Burlingame AL, Sun Y, Wang ZY (2011) PP2A activates brassinosteroidresponsive gene expression and plant growth by dephosphorylating BZR1. Nat Cell Biol 13(2):124-131. https://doi.org/10.1038/ncb2151

Thaler JS, Humphrey PT, Whiteman NK (2012) Evolution of jasmonate and salicylate signal crosstalk. Trends Plant Sci 17(5):260-270. https://doi.org/10.1 016/j.tplants.2012.02.010

Thines B, Harmon FG (2010) Ambient temperature response establishes ELF3 as a required component of the core Arabidopsis circadian clock. Proc Natl Acad Sci U S A 107(7):3257-3262. https://doi.org/10.1073/pnas.0911006107

Ueguchi-Tanaka M, Ashikari M, Nakajima M, Itoh H, Katoh E, Kobayashi M, Chow TY, Hsing YIC, Kitano H, Yamaguchi I, Matsuoka M (2005) GIBBERELLIN INSENSITIVE DWARF1 encodes a soluble receptor for gibberellin. Nature 437(7059):693-698. https://doi.org/10.1038/nature04028

Verma V, Ravindran P, Kumar PP (2016) Plant hormone-mediated regulation of stress responses. BMC Plant Biol 16(1):86. https://doi.org/10.1186/s12870-0160771-y

Vu LD, Gevaert K, De Smet I (2019a) Feeling the heat: searching for plant thermosensors. Trends Plant Sci 24(3):210-219. https://doi.org/10.1016/j.tpla nts.2018.11.004

Vu LD, Xu X, Gevaert K, Smet I (2019b) Developmental plasticity at high temperature. Plant Physiol 181(2):399-411. https://doi.org/10.1104/pp.19. 00652

Wasternack C, Feussner I (2018) The Oxylipin pathways: biochemistry and function. Annu Rev Plant Biol 69(1):363-386. https://doi.org/10.1146/a nnurev-arplant-042817-040440

Willige BC, Ghosh S, Nill C, Zourelidou M, Dohmann EMN, Maier A, Schwechheimer C (2007) The DELLA domain of GA INSENSITIVE mediates the interaction with the GA INSENSITIVE DWARF1A gibberellin receptor of Arabidopsis. Plant Cell 19(4):1209-1220. https://doi.org/10.1105/tpc.107. 051441

Won C, Shen X, Mashiguchi K, Zheng Z, Dai X, Cheng Y, Kasahara H, Kamiya Y, Chory J, Zhao Y (2011) Conversion of tryptophan to indole-3-acetic acid by TRYPTOPHAN AMINOTRANSFERASES OF ARABIDOPSIS and YUCCAs in Arabidopsis. Proc Natl Acad Sci U S A 108(45):18518-18523. https://doi.org/1 0.1073/pnas.1108436108

Xu C, Kohler TA, Lenton TM, Svenning JC, Scheffer M (2020) Future of the human climate niche. Proc Natl Acad Sci U S A 117(21):11350-11355. https://doi. org/10.1073/pnas.1910114117

Yin YH, Wang ZY, Mora-Garcia S, Li JM, Yoshida S, Asami T, Chory J (2002) BES1 accumulates in the nucleus in response to brassinosteroids to regulate gene expression and promote stem elongation. Cell 109(2):181-191. https://doi. org/10.1016/s0092-8674(02)00721-3

Zhang B, Holmlund M, Lorrain S, Norberg M, Bako L, Fankhauser C, Nilsson O (2017) BLADE-ON-PETIOLE proteins act in an E3 ubiquitin ligase complex to regulate PHYTOCHROME INTERACTING FACTOR 4 abundance. eLife 6:e26759. https://doi.org/10.7554/eLife.26759

Zhang LL, Li W, Tian YY, Davis SJ, Liu JX (2021a) The E3 ligase XBAT35 mediates thermoresponsive hypocotyl growth by targeting ELF3 for degradation in Arabidopsis. J Integr Plant Biol 63(6):1097-1103. https://doi.org/10.1111/ jipb.13107

Zhang LL, Luo A, Davis SJ, Liu JX (2021b) Timing to grow: roles of clock in thermomorphogenesis. Trends Plant Sci S1360-1385(21):00207-00207. https://doi.org/10.1016/j.tplants.2021.07.020
Zhang LL, Shao YJ, Ding L, Wang MJ, Davis SJ, Liu JX (2021c) XBAT31 regulates thermoresponsive hypocotyl growth through mediating degradation of the thermosensor ELF3 in Arabidopsis. Sci Adv 7(19):eabf4427. https://doi.org/1 $0.1126 /$ sciadv.abf4427

Zhao C, Liu B, Piao SL, Wang XH, Lobell DB, Huang Y, Huang MT, Yao YT, Bassu S, Ciais P, Durand JL, Elliott J, Ewert F, Janssens IA, Li T, Lin E, Liu Q, Martre P, Muller C, Peng SS, Penuelas J, Ruane AC, Wallach D, Wang T, Wu DH, Liu Z, Zhu Y, Zhu ZC, Asseng S (2017) Temperature increase reduces global yields of major crops in four independent estimates. Proc Natl Acad Sci U S A 114(35):9326-9331. https://doi.org/10.1073/pnas.1701762114

Zhao YD (2018) Essential roles of local auxin biosynthesis in plant development and in adaptation to environmental changes. Annu Rev Plant Biol 69(1):417435. https://doi.org/10.1146/annurev-arplant-042817-040226

Zhou Y, Xun Q, Zhang D, Lv M, Ou Y, Li J (2019) TCP transcription factors associate with PHYTOCHROME INTERACTING FACTOR 4 and CRYPTOCHROME 1 to regulate thermomorphogenesis in Arabidopsis thaliana. iScience 15:600610. https://doi.org/10.1016/j.isci.2019.04.002

Zhu T, Herrfurth C, Xin M, Savchenko T, Feussner I, Goossens A, Smet ID (2021) Warm temperature triggers JOX and ST2A-mediated jasmonate catabolism to promote plant growth. Nat Commun 12(1):4804. https://doi.org/10.1038/s414 67-021-24883-2

\section{Publisher's Note}

Springer Nature remains neutral with regard to jurisdictional claims in published maps and institutional affiliations. 